\title{
非晶質窒化ケイ素粉体の結晶化挙動
}

\author{
北條純一・前田英明 ${ }^{\dagger}$ ·加藤昭夫 \\ (九州大学工学部応用化学科, 812 福岡市東区箱崎 6-10-1)
}

\section{Crystallization Behavior of Amorphous Silicon Nitride Powder}

\author{
Junichi HOJO, Hideaki MAEDA ${ }^{\dagger}$ and Akio KATO \\ $\left(\begin{array}{l}\text { Department of Applied Chemistry, Faculty of Engineering, Kyushu University, } \\ \text { 6-10-1, Hakozaki, Higashi-ku, Fukuoka-shi } 812\end{array}\right.$
}

\begin{abstract}
Amorphous silicon nitride powder (particle size: $0.04 \mu \mathrm{m}$ ) obtained by the vapor phase reaction of $\mathrm{Si}\left(\mathrm{CH}_{3}\right)_{4}-\mathrm{NH}_{3}$ system was compacted into pellet and heat-treated in $N_{2}$ to investigate the crystallization behavior. The amorphous powder crystallized to $100 \% \alpha-S_{3} N_{4}$ by the heat treatment for $1 \mathrm{~h}$ at $1550^{\circ} \mathrm{C}$. The equiaxed crystalline particles having the size of $1-2 \mu \mathrm{m}$ were obtained when powder was compacted, whereas acicular particles were produced when powder was not compacted. When $\mathrm{Si}_{3} \mathrm{~N}_{4}$ powder was used as powder bed which covered pellet, the crystalline particles grew extensively and the crystallinity increased with a decrease in the packing fraction of particles in pellet. The heat-treated powder with a low crystallinity consisted of fine amorphous particles and coarse crystalline particles. The crystallization seemed to proceed by a vapor phase growth mechanism, in which $\mathrm{SiO}$ vapor takes part as silicon carrier between amorphous particles and crystalline ones. When $B N$ powder was used as powder bed, the crystallization and grain growth were retarded, and the crystal phase contained a small amount of $\beta-\mathrm{Si}_{3} N_{4}$. Crystallization inhibitor, e. g. boron oxide, may have penetrated into pellet from BN powder.
\end{abstract}

[Received February 10, 1988; Accepted April 26, 1988]

Key-words : Silicon nitride, Amorphous powder, Crystallization, Tetramethyl silane, CVD-powder

\section{1. 緒 言}

気相反応法やイミド熱分解法によって微細で金属不純 物の少ない窒化ケイ素粉体が合成できる。しかし，ほと んよ゙の場合，生成粉体は過剩の $\mathrm{N}, \mathrm{H}$ を含む非晶質であ り，Si-N 結合が不規則に配列した構造をとっていると 考えられている ${ }^{1)}$. したがって, 結晶質の窒化ケイ素粉 体を得るためには, 生成粉体の熱処理が必要である. 熱 処理は窒素雲囲気下, $1300^{\circ} \sim 1600^{\circ} \mathrm{C}$ で行われ, 主とし て $\alpha$ 相からなる結晶質窒化ケイ素が生成する ${ }^{2)-4)}$. しか しながら, 非晶質窒化ケイ素の結晶化機構についてはま だよくわかっていない.

これまで気相反応法のケイ素源として $\mathrm{SiCl}_{4}$ と $\mathrm{SiH}_{4}$ が，イミド熱分解法のケイ素源として $\mathrm{SiCl}_{4}$ が用いられ ているが, $\mathrm{SiCl}_{4}$ は腐食性が高く, $\mathrm{SiH}_{4}$ は爆発性, 毒性 があり, $\mathrm{SiCl}_{4}$ からの $\mathrm{Cl}$ や $\mathrm{SiH}_{4}$ からの $\mathrm{Si}$ の残留も問 題となる. 加藤ら ${ }^{1)}$ は $\mathrm{SiCl}_{4}-\mathrm{NH}_{3}$ 系とともに, $\mathrm{Si}\left(\mathrm{CH}_{3}\right)_{4}$ $\mathrm{NH}_{3}$ 系の気相反応による非晶質窒化ケイ素粉体の生成 についても報告している. $\mathrm{Si}\left(\mathrm{CH}_{3}\right)_{4}$ は安全性の高い液 体で, 蒸発量の制御も容易であり, CVD 用のケイ素源 として最近注目されている5 . 本研究では $\mathrm{Si}\left(\mathrm{CH}_{3}\right)_{4}-$ $\mathrm{NH}_{3}$ 系気相反応で合成した非晶質窒化ケイ素粉体の熱

†現在：三井鉱山（株），328-03 栃木市国府町 1

Now with Mitsui Mining Co., Ltd., 1, Kokufu-machi, Tochigi-shi $\quad 328-03$
処理を行い, その結晶化特性を調べた. そして, 熱処理 条件による結晶化率, 結晶相, 粒子径の変化から, 非晶 質窒化ケイ素の結晶化機構を検討した.

\section{2. 実験方法}

\section{1 原料粉体}

$\mathrm{Si}\left(\mathrm{CH}_{3}\right)_{4}(1 \%)-\mathrm{NH}_{3}(3 \%)-\mathrm{H}_{2}$ 系の気相反応 (反応温 度 $\left.1200^{\circ} \mathrm{C}\right)$ により, 窒化ケイ素粉体を合成した。透過 型電子顕微鏡観察により求めた個数平均径は $0.04 \mu \mathrm{m}$ であった．粉末 X 線回折でピークが認められず，生成 物は非晶質であった。ケルダール法で窒素量を, 酸化燃 焼法で炭素量とケイ素量を測定したところ, 乾燥試料基 準での化学組成は $\mathrm{Si}=35.2 \mathrm{~mol} \%, \mathrm{~N}=47.2 \mathrm{~mol} \%, \mathrm{C}$ $=7.8 \mathrm{~mol} \%$ であった. 化学組成の物質収支不足分

$(9.8 \mathrm{~mol} \%)$ は, 空気中での粒子表面の酸化による不 純物酸素の含有のためと考えられる. 赤外線吸収スペク トルでは $\mathrm{SiH}_{x}$ 基, $\mathrm{NH}_{x}$ 基及び $\mathrm{CH}_{x}$ 基は検出されなかっ た.

\section{2 熱処理}

粉体試料は直径 $10 \mathrm{~mm}$, 厚さ $1 \sim 2 \mathrm{~mm}$ のペレットに 成形した. 試料をMo 容器に入れ, それをアルミナボー ト内に置いた. ペレットを市販の $\alpha-\mathrm{Si}_{3} \mathrm{~N}_{4}$ 粉体 (Herman C. Starck 製) 又は h-BN 粉体 (和光純薬工業製) で覆っ た実験（パウダーベッド法）も行った. ボートを再結晶 
アルミナ管内に置いて炭化ケイ素抵抗炬で加熱し, $\mathrm{N}_{2}$ (1 atm) 気流中, $1500^{\circ}$ と $1550^{\circ} \mathrm{C}$ で熱処理を行った. 所定温度までの昇温速度は $10^{\circ} \mathrm{C} / \mathrm{min}$ 又は $300^{\circ} \mathrm{C} / \mathrm{min}$ とした.

\section{3 分 析}

粉末 X 線回折 (Co $K \alpha$ 線) により結晶相の同定と定 量を行った。結晶相の定量は $\mathrm{NaCl}$ を用いた内部標準法 で行い, $\alpha-\mathrm{Si}_{3} \mathrm{~N}_{4}(201), \quad \beta-\mathrm{Si}_{3} \mathrm{~N}_{4}(200), \mathrm{NaCl}(200)$ の 各回折線を使用した。結晶相全体の重量分率を結晶化率 とした. 透過型電子影微鏡 $(T E M)$ 及び走査型電子顕 微鏡 $(\mathrm{SEM})$ により粒子形態を観察した.

\section{3. 結果と考察}

\section{1 非晶質窒化ケイ素の結晶化速度}

$\mathrm{SiH}_{4}-\mathrm{NH}_{3}$ 系気相反応により合成された非晶質窒化ケ イ素粉体の結晶化は $1480^{\circ} \mathrm{C}$ 以上で起こることが報告さ れている2). $\mathrm{SiCl}_{4}-\mathrm{NH}_{3}$ 系のプラズマ気相反応による非 晶質窒化ケイ素粉体でも, $1500^{\circ} \mathrm{C}$ 付近から結晶化が著 しくなることが報告されている3). いずれの場合も, 結 晶相はほとんど $\alpha-\mathrm{Si}_{3} \mathrm{~N}_{4}$ である.

図 1 に $\mathrm{Si}\left(\mathrm{CH}_{3}\right)_{4}-\mathrm{NH}_{3}$ 系から得た非晶質窒化ケイ素粉 体の $1500^{\circ}$ 及び $1550^{\circ} \mathrm{C}$ 熱処理における結晶化率の時間 変化を示す. 結晶相は $\alpha-\mathrm{Si}_{3} \mathrm{~N}_{4}$ のみであった. 熱処理温 度が $1500^{\circ} \mathrm{C}$ では結晶化速度が小さいが， $1550^{\circ} \mathrm{C}$ では 1 時間の熱処理で結晶化率は $100 \%$ に達した。本実験の 非晶質窒化ケイ素粉体の結晶化が著しくなる温度は, 従 来の気相法生成物亡大体一致している. 本実験試料は $\mathrm{Si}\left(\mathrm{CH}_{3}\right)_{4}$ のメチル基由来の炭素が残留しているが, 結 晶化速度に対する不純物炭素の影響は小さいとみられ る. 熱処理試料で $\mathrm{SiC}$ 相は検出されなかった. 熱処理後, 不純物炭素は遊離炭素亡して残存するか, あるいは試料 に含まれている不純物酸素と反応して除去されたと考え

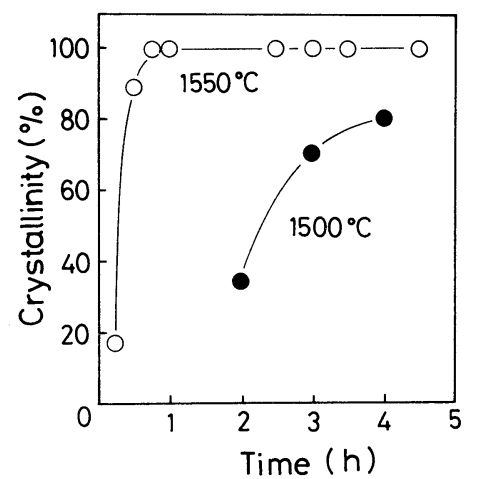

Fig. 1. Change in crystallinity with time during the heat treatment of amorphous silicon nitride powder at $1500^{\circ}$ and $1550^{\circ} \mathrm{C}$ in $\mathrm{N}_{2}$.

Compaction pressure of pellet $=1.5 \mathrm{t} / \mathrm{cm}^{2}$, Heating rate $=300^{\circ} \mathrm{C} / \mathrm{min}$
られる。

\section{2 パウダーベッドの効果}

粉体試料をペレットに成形せずに熱処理を行った場 合, 熱処理生成物はウイスカー状の $\alpha-\mathrm{Si}_{3} \mathrm{~N}_{4}$ であった。 また，ペレット試料でもその表面にウイスカーが生成し た. 金属ケイ素の窒化においても $\alpha-\mathrm{Si}_{3} \mathrm{~N}_{4}$ ウイスカーの 生成がみられ，その生成機構は気相成長機構で, 気相ヶ イ素成分として不純物酸素によって生成する $\mathrm{SiO}(\mathrm{g})$ が考えられている ${ }^{6)}$. そこで, 雾囲気がス $\left(\mathrm{N}_{2}\right)$ 中の不 純物酸素から試料を保護する目的でパウダーベッド法に よりペレット試料の熱処理を行った.

図 2 に $\mathrm{Si}_{3} \mathrm{~N}_{4}$ 粉体と $\mathrm{BN}$ 粉体をパウダーベッドに用い て， $1550^{\circ} \mathrm{C}$ で熱処理したときの結晶化率の時間変化を 示す. $\mathrm{Si}_{3} \mathrm{~N}_{4}$ 粉体をパウダーベッドに用いた場合，パウ ダーベッドを用いない場合と比べて結晶化速度に変化は なかった. 一方, BN 粉体をパウダーベッドに用いた場 合，結晶化速度が著しく減少し，結晶化率が $100 \%$ にな るのに 3.5〜4 時間を要した. また, ペレットの表層部 と内部の X 線回折を行ったところ, 表層部の方が結晶 化が遅いことがわかった. 更に, 結晶化率 $100 \%$ の生成

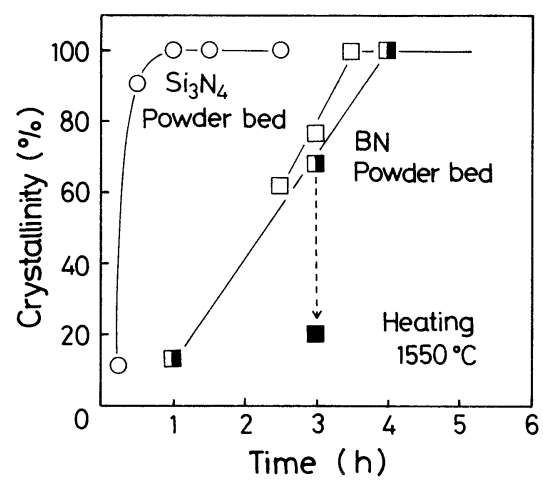

Fig. 2. Effects of $\mathrm{Si}_{3} \mathrm{~N}_{4}$ and $\mathrm{BN}$ powder beds.

$\bigcirc, \square$ : Compaction pressure of pellet $(P)=1.5 \mathrm{t} / \mathrm{cm}^{2}$, Heating rate $(R)=300^{\circ} \mathrm{C} / \mathrm{min}$

W: $P=1.5 \mathrm{t} / \mathrm{cm}^{2}, \quad R=10^{\circ} \mathrm{C} / \mathrm{min}$

口: $P=0.5 \mathrm{t} / \mathrm{cm}^{2}, \quad R=10^{\circ} \mathrm{C} / \mathrm{min}$

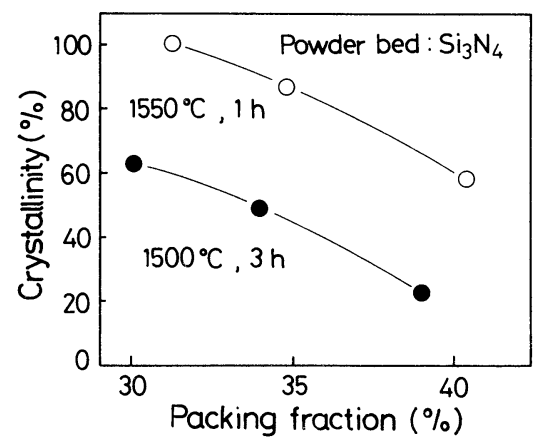

Fig. 3. Effect of the packing fraction of particles. Compaction pressure of pellet $=1.5-4 \mathrm{t} / \mathrm{cm}^{2}$, Heating rate $: 300^{\circ} \mathrm{C} / \mathrm{min}$ 
物は $\alpha$ 相以外に約 $10 \% の \beta$ 相を含んでいた。

以上のように，パウダーベッドに $\mathrm{Si}_{3} \mathrm{~N}_{4}$ 粉体を用いた 場合と BN 粉体を用いた場合とで, 非晶質窒化ケイ素 の結晶化速度と結晶相に大きな違いがみられた.しかし， パウダーベッドを用いた場合でも，ペレット表面にウイ スカーの生成が認められ，SiO 源は試料の表面酸化層 と考えられる。

\section{3 粒子充媜率の効果}

ペレットの成形圧力により粒子充填率を変化させ，非 晶質窒化ケイ素粉体の結晶化に対する影響を調べた。粒 子充填率はペレットの重量と寸法とから， $\alpha-\mathrm{Si}_{3} \mathrm{~N}_{4}$ の密 度を基準にして求めた。

$\mathrm{Si}_{3} \mathrm{~N}_{4}$ 粉体をパウダーベッドに用いた場合の $1500^{\circ}$ よ $1550^{\circ} \mathrm{C}$ での結晶化率とペレットの粒子充填率の関係を 図 3 に示す．粒子充填率が低いほうが結晶化率が高い。 一方， $\mathrm{BN}$ 粉体をパウダーベッドに用いた場合，図 2 に ペレットの成形圧を小さくしたときの結晶化率を示して いるが，粒子充填率の低下により結晶化速度が小さく なった。このように，結晶化速度に対する粒子充填率の 効果は，パウダーベッドに $\mathrm{Si}_{3} \mathrm{~N}_{4}$ 粉体を用いた場合之 $\mathrm{BN}$ 粉体を用いた場合とで逆に現れる。

\section{4 熱処理粉体の粒子形態}

熱処理後のペレット内部を SEM で観察したところ， 結晶化粒子はほぼ等軸状の粒子であった．図4 に熱処理 粉体の SEM 写真を例示する.

結晶化率が低い場合，粒径が $1 \sim 2 \mu \mathrm{m}$ の大粒子及び 原粒子と同程度の大きさの微粒子が混在していた（図 4 (A))．結晶化の進行とともに微粒子の割合が減少し， 結晶化率 100\%では大粒子のみとなった（図 4 (B)， (C)). Sawhill ら 及び山田ら ${ }^{8)}$ は，非晶質窒化ケイ素 粉体を熱処理したとき，結晶化度の低い熱処理粉体が微
細な非晶質粒子と大きな結晶質粒子とからなることを報 告している. 本実験の低結晶性試料でみられた微粒子も 非晶質粒子と考えられる。結晶化率が $100 \%$ に到達し， 大粒子のみとなったのち，長時間加熱しても粒径はほと んど変化しなかった。このように，粒成長は結晶化と同 時に進行している，パウダーベッドを用いなかった場合 (図 4 (B)) に比べて, $\mathrm{Si}_{3} \mathrm{~N}_{4}$ 粉体をパウダーベッドに 用いた場合（図 $4(C))$ のほうが結晶化粒子の粒径が大 きい，熱処理によって維密化は起こらなかったが，成長 粒子間の局部的な焼結がみられた。

$\mathrm{BN}$ 粉体をパウダーベッドに用いた場合，熱処理後の ペレットを軽く解砕して粒子形態を TEM で観察した ところ，結晶化率 $100 \%$ で粒径は $0.1 \sim 0.3 \mu \mathrm{m}$ であり， パウダーベッドを用いなかった場合に比べて粒成長が抑 制されていた。

\section{5 結晶化機構}

Prochazka ら ${ }^{21}$ は $\mathrm{SiH}_{4}-\mathrm{NH}_{3}$ 系気相反応による非晶質 窒化ケイ素粉体の熱処理を行い，結晶化は非晶質粒子内 での核生成之成長により進行する之述べている。山田 ら ${ }^{4)}$ はイミド熱分解による非晶質窒化ケイ素粉体の結晶 化について， $1430^{\circ} \mathrm{C}$ 以下での等軸状粒子の生成に対し ては固相内での核生成之成長の機構を, $1430^{\circ} \mathrm{C}$ 以上で の針状粒子の生成に対しては気相成長機構を提案してい る. 3.4 節で述べたように，結晶化度の低い熱処理粉体 は微細な非晶質粒子と大きな結晶質粒子とからなってい る．このことは，非晶質粒子内で結晶成長が進行する固 相機構では説明できず，結晶化は主に粒子間での物質移 動により進行していると考えられる、そのときの物質移 動過程としては，粒子間の接触点を通しての表面拡散， 又は気相を通しての蒸気拡散が考えられる。

$\mathrm{Si}_{3} \mathrm{~N}_{4}$ 粉体をパウダーベッドに用いた場合，試料ペ

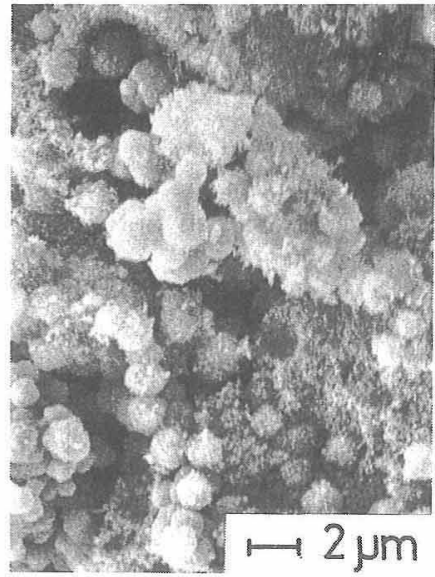

(A) $\mathrm{Y}=89 \%$

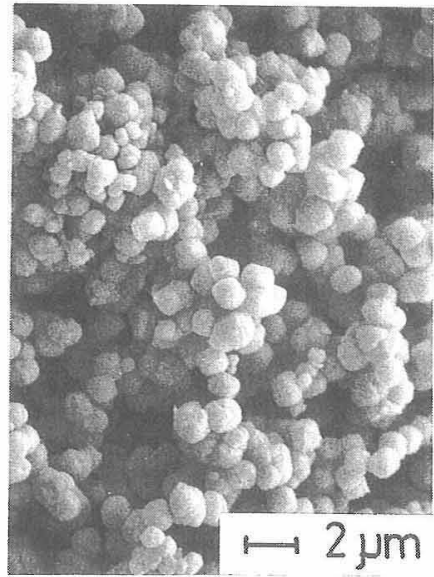

(B) $\mathrm{Y}=100 \%$

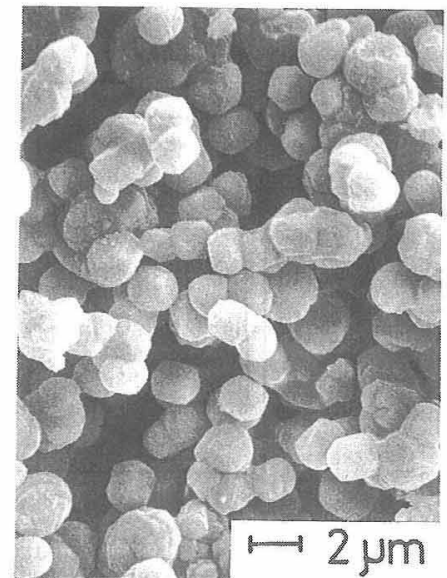

(C) $Y=100 \%$

Fig. 4. SEM photographs of heat-treated powder ( $\mathrm{Y}$ : crystallinity). Heating temperature $=1550^{\circ} \mathrm{C}$

(A) Heating time $(t)=0.5 \mathrm{~h}$, (B) $t=1 \mathrm{~h}$, (C) $t=1 \mathrm{~h}\left(\mathrm{Si}_{3} \mathrm{~N}_{4}\right.$ powder bed) 
レットの粒子充填率の増加によって結晶化率が低下し た.この結果は, 粒子の接触点数の増加が結晶化に寄与 しないことを示しており, 表面拡散による物質移動過程 では説明できない。むしろ,粒子間の気孔径の減少によっ て繁気拡散による物質移動が抑制されたと考えるのが妥 当である。山田ら ${ }^{4)}$ は気相成長機構により針状粒子が生 成すると報告しているが，本実験では等軸状粒子が生成 した。これは，前者では粉体試料を成形せずに熱処理し ているのに対して，後者では粉体を成形しており，ウイ スカーの成長に必要な空間容積が小さくなったためであ ろう. 本研究でもペレット試料の表面にはウイスカーの 生成が認められた。

以上のことから，本実験での非晶質窒化ケイ素粉体の 主要な結晶化機構として気相成長機構を考えた。結晶化 温度が窒化ケイ素の分解温度 $\left(1800^{\circ} \sim 1900^{\circ} \mathrm{C}\right)$ 上りか なり低いので, 介在する気相ケイ素成分としては, 3.2 節で述べたように試料粉体の表面酸化層から発生する $\mathrm{SiO}$ 蒸気が考えられる. 気相からの析出反応により， まず非晶質粒子表面に窒化ケイ素の不均一核が生成し, それを起点として結晶成長が進行すると考えられる。図 5 に SiO なんた気相成長機構による結晶化のモデル と関連反応を示す。加熱初期において, $\mathrm{SiO}$ は表面酸 化層と非晶質窒化ケイ素の反応により生成する。生成し た $\mathrm{SiO}$ は気相を拡散し, 成長結晶表面で $\alpha-\mathrm{Si}_{3} \mathrm{~N}_{4}$ の析 出反応が起こる. 反応の進行とともに非晶質粒子表面の 酸化層は消失するが, $\mathrm{SiO}$ からの $\alpha-\mathrm{Si}_{3} \mathrm{~N}_{4}$ の析出反応に より $\mathrm{O}_{2}$ が副生し， $\mathrm{O}_{2}$ による非晶質粒子の酸化により $\mathrm{SiO}$ が生成するため, $\alpha-\mathrm{Si}_{3} \mathrm{~N}_{4}$ の析出反応と $\mathrm{SiO}$ の生成 反応のサイクルが形成され，結晶成長が引き続き進行す る. 結晶化速度は粒子充媜率に低存しており, 気相成分 の拡散が律速と考えられる. $\mathrm{Si}_{3} \mathrm{~N}_{4}$ 粉体をパウダーベッ ドに用いた場合，パウダーベッドを用いない場合と比ベ て結晶化速度には差が認められないが, 結晶粒子が大き

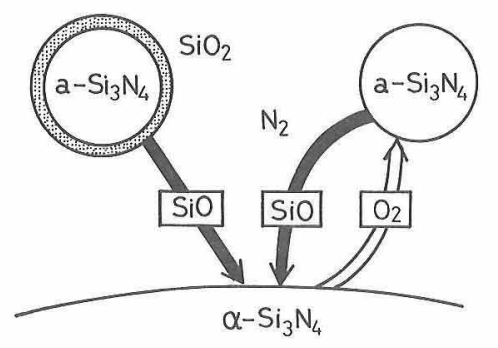

$$
\begin{aligned}
& a-\mathrm{Si}_{3} \mathrm{~N}_{4}(\mathrm{~s})+\mathrm{SiO}_{2}(\mathrm{~s}) \rightarrow \mathrm{SiO}(\mathrm{g})+\mathrm{N}_{2}(\mathrm{~g}) \\
& \mathrm{SiO}(\mathrm{g})+\mathrm{N}_{2}(\mathrm{~g}) \rightarrow \alpha-\mathrm{Si}_{3} \mathrm{~N}_{4}(\mathrm{~s})+\mathrm{O}_{2}(\mathrm{~g}) \\
& \mathrm{O}_{2}(\mathrm{~g})+\mathrm{a}-\mathrm{Si}_{3} \mathrm{~N}_{4}(\mathrm{~s}) \rightarrow \mathrm{SiO}(\mathrm{g})+\mathrm{N}_{2}(\mathrm{~g})
\end{aligned}
$$

Fig. 5. Schematic model of the crystallization process of amorphous silicon nitride powder by vapor phase growth mechanism and the relating reactions.
くなった。これは, パウダーベッドによって $\mathrm{SiO} や \mathrm{O}_{2}$ が試料ペレット内に閉じ込められることと，パウダー ベッドからの $\mathrm{SiO}$ の供給によって，成形体試料内でそ れら気相成分が高濃度となり，粒成長速度が増大するた めであろう。

$\mathrm{BN}$ 粉体をパウダーベッドに用いた場合, 結晶化並び に粒成長が抑制され，その抑制の程度は試料ペレットの 内部より表面層で，また粒子充填率の低い方が著しい， これらのことは，BN 粉体に由来する結晶化抑制物質が ペレット内に侵入することを示している。この場合，結 晶化試料は $\alpha-\mathrm{Si}_{3} \mathrm{~N}_{4}$ のほか少量の $\beta-\mathrm{Si}_{3} \mathrm{~N}_{1}$ を含んでい た. $\alpha$ 相から $\beta$ 相への転移は液相を介して起こるといわ れている ${ }^{9 !}$. 本実験では BN 粉体の表面酸化層の蒸発, あるいは雲囲気中の不純物酸素と BN の反応で生成す るホウ素酸化物がペレット内に侵入し，ヶイ素酸化物と の間に液相を形成した可能性がある. 例えば, $\mathrm{SiO}_{2}-\mathrm{B}_{2} \mathrm{O}_{3}$ 系状態図 ${ }^{10}$ において, $1550^{\circ} \mathrm{C}$ では約 4 wt \% の $\mathrm{B}_{2} \mathrm{O}_{3}$ の存在で液相が生成する.したがって, 結晶化 抑制機構としては，液相が非晶質粒子表面を被覆し， $\mathrm{SiO}$ の発生を抑制することが考えられる。

以上のように, 本実験の非晶質窒化ケイ素粉体の結晶 化特性は気相成長機構によって最もよく説明できる。山 田ら ${ }^{4)}$ はLS 機構を提案しているが，BN 粉体をパウ ダーベッドに用いたとき以外は生成相が $\alpha$ 相のみで $\beta$ 相がないことから，不純物液相の関与はないと考えられ る.なお, 気相成長機構は気相ケイ素成分の蒸発量が多 くなる高温で優勢な機構であり，低温では固相機構によ る結晶化も考えられる。

\section{4. 総 括}

$\mathrm{Si}\left(\mathrm{CH}_{3}\right)_{4}-\mathrm{NH}_{3}$ 系気相反応により合成した粒径 0.04 $\mu \mathrm{m}$ の非晶質空化ケイ素粉体をペレットに成形し, $\mathrm{N}_{2}$ 中， $1500^{\circ}-1550^{\circ} \mathrm{C}$ で熱処理を行い，結晶化特性を調べた。 結果は次のとおりである。

（1）非晶質粉体は $1550^{\circ} \mathrm{C}, 1$ 時間の熱処理によっ て， $100 \% \alpha-\mathrm{Si}_{3} \mathrm{~N}_{4}$ へ結晶化した。粉体を成形しないと きには針状粒子が生成するがペレットに成形すること により粒径 1-2 $\mu \mathrm{m}$ の等軸状の結晶化粒子が得られた。

(2) $\mathrm{Si}_{3} \mathrm{~N}_{4}$ 粉体をパウダーベッドに用いることによ り，結晶化粒子がより大きく成長した。また，武料ペレッ トの粒子充填率を小さくすると結晶化率が高くなった。

（3）結晶化度の低い熱処理粉体は微細な非晶質粒子 と大きな結晶質粒子とからなっている. 結晶化は $\mathrm{SiO}$ 蒸気を非晶質粒子と結晶質粒子の間のケイ素キャリアと する気相成長機構により進行すると考えられる。

（4） BN 粉体をパウダーベッドに用いた場合, 結晶 化並びに粒成長が抑制され，結晶相は少量の $\beta-\mathrm{Si}_{3} \mathrm{~N}_{4}$ を 含んでいた。 $\mathrm{BN}$ 粉体からホウ素酸化物のような結晶化 
抑制物質が試料ペレット内へ侵入したと考えられる。

\section{文献}

1）加藤昭夫, 小野吉弘, 川添早苗, 持田 勲, 窯協, 80 , 114-20 (1972).

2) S. Prochazka and C. Greskovich, Am. Ceram. Soc. Bull., 57, 579-86 (1978).

3）二木昌次, 白石勝造, 清水忠義, 吉田豊信, 窯協, 94, 7-11 (1986)

4) T. Yamada, T. Kawahito and T. Iwai, J. Mater. Sci.
Lett., 2, 275-78 (1983).

5) J.F. Lartigue, M. Ducarroir and B. Armas, Proc. Int. Conf. Chem. Vapor Deposition, 9, 561-74 (1984).

6) D. R. Messier and P. Wong, J. Am. Ceram. Soc., 56, 480-85 (1973).

7) H. T. Sawhill and J.S. Haggerty, J. Am. Ceram. Soc., 65, C131-32 (1982).

8）山田哲夫, 桝永勝朗, 国沢哲郎, 神徳泰彦, 㝘協, 93, 394-97 (1985).

9) D. R. Messier, F. L. Riley and R. J. Brook, J. Mater. Sci., 13, 1199-205 (1978).

10) T. J. Rockett and W. R. Foster, J. Am. Ceram. Soc., 48, 75-80 (1965). 